\title{
BREVES APUNTES SOBRE LA INFERENCIA PROBATORIA COMO MECANISMO DE JUSTIFICACIÓN DE LAS RESOLUCIONES JUDICIALES PARA LA TUTELA DE LOS DERECHOS FUNDAMENTALES
}

\section{BRIEF NOTES OF THE EVIDENTIARY ASSESSMENT AS A JUSTIFICATION MECHANISM OF JUDICIAL RESOLUTIONS FOR THE PROTECTION OF FUNDAMENTAL RIGHTS}

Dante Torres Altez* Pontificia Universidad Católica del Perú

\section{Resumen}

Tanto el derecho a la prueba y a la motivación de las resoluciones judiciales logran trabajar juntos de tal forma que permitan al juzgador realizar un adecuado y racional estudio de los hechos para lograr una decisión que logre el necesario respeto de los derechos fundamentales.

Palabras clave: Derecho a la prueba, motivación de las resoluciones judiciales, tutela jurisdiccional efectiva, debido proceso, libre valoración de la prueba, racionalidad.

\section{Abstract}

The right of evidence and the motivation of the judicial resolutions manage to work together in such a way that they allow the judge to make a correct and rational study of the facts to obtain a decision that achieves the necessary respect of the Fundamental rights.

Keywords: Right of evidence, motivation of judicial resolutions, effective judicial protection, due process, free evaluation of evidence, rationality.

Coordinador de la Academia de la Magistratura, sede Junín. Profesor en la Universidad Peruana Los Andes. 


\section{INTRODUCCIÓN}

No cabe duda que uno de los problemas principales en la construcción de una decisión justa es la adecuada motivación de las resoluciones judiciales, y para la existencia —a su vez- de dicha motivación es necesario que los jueces realicen una adecuada valoración de los medios probatorios, es decir, que su decisión esté basada en armonía y contraste con las reglas de inferencia probatoria.

Sólo cuando esto ocurre, estaremos ante la protección que el Estado debe proporcionar a los justiciables. Sin embargo, mientras exista un incumplimiento a este poder-deber del Estado, representado en la labor jurisdiccional de los jueces, se manifestará una clara y directa vulneración al debido proceso y consecuentemente al derecho fundamental a la tutela judicial efectiva.

En esta breve reflexión, analizaremos cómo influye frontalmente el respeto a las reglas de la sana crítica — como sistema de valoración de prueba- en las decisiones de los jueces, aterrizando en el análisis de una sentencia del Tribunal Constitucional, en la que podemos apreciar la clara afectación a dichas reglas de valoración mínimas y la motivación de las resoluciones judiciales en que incurrieron los jueces del Poder Judicial.

\section{PROBLEMA}

Surge como interrogante si es necesario o no establecer parámetros al momento de realizar la valoración de los medios probatorios y evitar arbitrariedades al momento de motivar una resolución judicial.

\section{DESARROLLO}

\subsection{Motivación, tutela judicial y proceso debido}

Con la constitucionalización de la tutela jurisdiccional de los derechos, el vínculo entre derecho procesal y material se ha reducido al mínimo, pues se ha llegado a entender, de una vez por todas, que el proceso está diseñado para que el Estado-juez pueda tutelar los derechos materiales. Esta comprensión no ha sido fácil desde que los estudios de derecho procesal han sido abordados aisladamente, sin la intervención ni conexión con otras disciplinas. Su clara negación con estudios de derecho constitucional o de la teoría del derecho han determinado que el proceso se vea limitado como 
un simple instrumento secundario para algo más importante: el derecho material. Sin embargo — como decíamos-, la llegada del constitucionalismo ha influenciado no sólo el estudio del proceso diametralmente, sino que ha permitido recortar la brecha de otras disciplinas.

En ese sentido, se ha comprendido en nuestro país que la finalidad del proceso es la defensa del derecho a la dignidad como fin supremo del Estado (Constitución Política del Perú, Art. 1) y que el estudio y preocupación por la exigencia a la motivación de las resoluciones judiciales es el reflejo de la protección al derecho fundamental del debido proceso y la tutela jurisdiccional efectiva.

El derecho a la tutela jurisdiccional efectiva desde los derechos fundamentales ha permitido comprender la preocupación de la efectividad y seguridad de la tutela de los derechos, con la participación de técnicas de interpretación y motivación para la emisión de una decisión justa (Alvaro, 2008, p. 63-83).

$\mathrm{Al}$ respecto y desde esta comprensión, la tutela jurisdiccional efectiva es el derecho que tiene todo sujeto de derecho de acceder a un órgano jurisdiccional para solicitar la protección de una situación jurídica que se alega que está siendo vulnerada o amenazada a través de un proceso dotado de las mínimas garantías, luego del cual se expedirá una resolución fundada en derecho con posibilidad de ejecución (Priori, 2003, p. 280).

Desde esa comprensión, el derecho a la tutela jurisdiccional efectiva integra los siguientes derechos: el derecho de acceder a los órganos jurisdiccionales, el respecto a las garantías mínimas procesales constitucionales - debido proceso-motivación de las resoluciones judiciales-y la efectividad o realización de las decisiones en el plano material.

En cuanto al derecho al debido proceso y la tutela jurisdiccional efectiva, han sido abordados desde diversos puntos de vista a nivel de la doctrina peruana. Particularmente, nos adherimos a la mayoritaria, que tiene al debido proceso como una manifestación del derecho a la tutela jurisdiccional efectiva (Eguiguren, 1999; Monroy, 2008; Ticona, 1999).

Puede considerarse que este derecho a una efectiva tutela judicial comprende tres aspectos: en primer lugar, un derecho de los justiciables de acción y acceso real, libre, amplio e irrestricto a la prestación jurisdiccional del órgano estatal competente; en segundo lugar, a que la atención de las 
prestaciones se desarrolle conforme a las reglas del debido proceso, es decir, según las normas vigentes y los estándares aceptados como necesarios para hacer posible la eficacia del derecho; $y$, en tercer lugar, a la efectividad de la sentencia, es decir, a que el proceso concluya en una resolución final, la misma que debe estar arreglada a derecho y dotada de un contenido mínimo de justicia, decisión esta que debe ser susceptible de ser ejecutada con coercitividad (Eguiguren, 1999, p. 97).

Para el profesor Monroy, el derecho a la tutela jurisdiccional efectiva puede ubicarse antes del proceso y durante el proceso, encontrándose en este último al debido proceso. Sin embargo, señala «en nuestra opinión entre el derecho a la tutela jurisdiccional efectiva y el derecho al debido proceso, existe la misma relación que se presenta entre la anatomía y la fisiología cuando se estudia un órgano vivo, es decir, la diferencia sólo reside en la visión estática y dinámica de cada disciplina, respectivamente. El primero es postulado, la abstracción; en cambio, el segundo es la manifestación concreta del primero» (Monroy, 2008, pp. 459 y 460).

Según Ticona (1999), «[E]l derecho a la tutela jurisdiccional efectiva es un derecho genérico que, a su vez, comprende tres derechos fundamentales específicos: de acción, de contradicción o defensa en general y derecho al debido proceso» (p. 61).

Asimismo, el Tribunal Constitucional se ha pronunciado en ese sentido, según el cual se refleja la tesis doctrinaria de que el debido proceso forma parte integrante del derecho a la tutela jurisdiccional efectiva (Sentencias recaídas en los expedientes N. ${ }^{\text {ss }}$ 615-1999-AA/TC y 1230-2002-HC/TC).

Pero ¿qué es el derecho al debido proceso? Es un derecho humano de naturaleza procesal que busca resolver las controversias de que se presentan en los tribunales de justicia. Se considera un derecho continente, pues engloba una serie de garantías formales y materiales con contenido constitucional.

Para resumir la comprensión de este derecho, citaremos la jurisprudencia del Poder Judicial, del Tribunal Constitucional y la Corte Interamericana de Derechos Humanos, haciendo énfasis en el derecho a la prueba y a la motivación de resoluciones judiciales como derechos y garantías constitucionales.

El derecho a la prueba está consagrado en el numeral 3 del artículo 139 de la Constitución Política del Estado, que asegura que los justiciables realicen 
la actuación anticipada de los medios probatorios que consideren necesarios para convencer al juez sobre la veracidad de sus argumentos, y que este valore las pruebas de manera adecuada y motivada.

Eso quiere decir que toda prueba, para ser valorada en un proceso, debe reunir ciertas características: 1) Veracidad objetiva, en virtud de la cual la prueba debe reflejar de manera exacta lo acontecido en la realidad, esto es, con la finalidad de asegurar que el elemento probatorio se ajuste a la verdad y no haya sido manipulado; 2) Constitucionalidad de la actividad probatoria, la cual prohíbe la obtención, recepción y valoración de pruebas que vulneren derechos fundamentales o transgredan el orden jurídico; 3) Utilidad de la prueba, que verifica la utilidad de la prueba siempre que esta produzca certeza judicial para la resolución del caso; 4) Pertinencia de la prueba, según la cual la prueba se reputará pertinente si guarda relación directa con el objeto del procedimiento.

No obstante lo referido, lo que nos genera mayor interés es la importancia de la valoración de prueba como mecanismo para la existencia de una motivación eficiente de las resoluciones judiciales. Para ello, el ordenamiento procesal ha enfatizado que:

[E]l Código Adjetivo ha adoptado el sistema de la libre valoración, señalando que los medios probatorios deben ser valorados en forma conjunta y merituados en forma razonada, lo cual no implica que el Juzgador, al momento de emitir sentencia, deba señalar la valoración otorgada a cada prueba actuada, sino únicamente lo hará respecto a los medios probatorios que de forma esencial y determinada han condicionado su decisión [...]. (Considerando noveno de la Casación N. ${ }^{\circ} 823-2010$ del 27 de enero del 2011, emitida por la Sala Civil Permanente).

Lo que significa que la valoración de las pruebas se realiza al momento de sentenciar, derivando una exigencia elevada al Estado-juez dentro del marco del respeto a los derechos fundamentales y la normatividad para la necesidad de utilizar criterios objetivos y razonables, y así darle sentido o valor jurídico a sus decisiones.

En esa sintonía, está el respeto a la motivación de las resoluciones judiciales, cuando el numeral 5 del artículo 139 de la Constitución Política, concordante con el artículo 12 de la Ley Orgánica del Poder Judicial, y numerales 3 y 4 del artículo 122 y 50, numeral 6, del Código Procesal Civil, dispone que toda resolución emitida por cualquier instancia judicial debe encontrarse debidamente motivada. Es decir, debe manifestarse en 
los considerandos la radio decidendi que fundamenta la decisión, la cual debe contar — por ende - con los fundamentos de hecho y derecho que expliquen por qué se ha resuelto de tal o cual manera. Solo conociendo de manera clara las razones que justifican la decisión, los destinatarios podrán ejercer los actos necesarios para defender su pretensión.

Así, la Corte Suprema de la República señaló:

[L]a motivación de las resoluciones judiciales como principio y derecho de la función jurisdiccional [...], es esencial en las decisiones judiciales, en atención a que los justiciables deben saber las razones por las cuales se ampara o desestima una demanda, pues a través de su aplicación efectiva se llega a una recta administración de justicia, evitándose con ello arbitrariedades y además permitiendo a las partes ejercer adecuadamente su derecho de impugnación, planteando al superior jerárquico, las razones jurídicas que sean capaces de poner de manifiesto, los errores que puede haber cometido el Juzgador. (Considerando sétimo de la Casación N. o 918-2011 Santa del 17 de mayo del 2011. emitida por la Sala Civil Transitoria)

Por su parte, el Tribunal Constitucional peruano ha engarzado estos dos derechos fundamentales, el de la prueba [valoración de prueba] con el de motivación de las resoluciones judiciales,

[E]stá compuesto por el derecho a ofrecer medios probatorios que se consideren necesarios, a que estos sean admitidos, adecuadamente actuados, que se asegure la producción o conservación de la prueba a partir de la actuación anticipada de los medios probatorios y que estos sean valorados de manera adecuada y con la motivación debida con el fin de darle el mérito probatorio que tenga en la sentencia. La valoración de la prueba debe estar debidamente motivada por escrito, con la finalidad de que el justiciable pueda comprobar si dicho mérito ha sido efectiva y adecuadamente realizado. (Fundamento 15 de la sentencia recaída em el expediente N. ${ }^{\circ} 06712-2005-\mathrm{HC} / \mathrm{TC}$ ).

Con ello, se ha comprendido plenamente, en la jurisprudencia de las altas cortes de nuestro país, que el vínculo entre la valoración de los medios probatorios con la motivación de las resoluciones judiciales constituye piedra angular para la defensa y protección de los derechos fundamentales. Pero no sólo este vínculo ha sido considerado como rasgo esencial en la jurisprudencia nacional, sino también tiene eco en el ámbito internacional, específicamente, nos referimos, a la Corte Interamericana de Derechos Humanos, al considerar que el análisis probatorio que se efectúa en el procedimiento contencioso interamericano no se encuentra sujeto a formalidades preestablecidas. La valoración del material probatorio se analiza de 
manera libre y de acuerdo con la sana crítica teniendo en cuenta para ello, principalmente, la pertinencia de su contenido con la acreditación de los hechos alegados (Caso Masacre de Maripian vs. Colombia. Sentencia del 15 de septiembre del 2005, párrafo 73). En efecto, desde su jurisprudencia originaria, la Corte Interamericana de Derechos Humanos ha señalado que:

La Corte debe determinar cuáles han de ser los criterios de valoración de las pruebas aplicables en este caso. Ni la Convención ni el Estatuto de la Corte o su Reglamento tratan esta materia. Sin embargo, la jurisprudencia internacional ha sostenido la potestad de los tribunales para evaluar libremente las pruebas, aunque ha evitado siempre suministrar una rígida determinación del quantum de prueba necesario para fundar el fallo [...]. (Caso Velásquez Rodríguez. Sentencia del 29 de julio de 1998, párrafo 127).

Asimismo, en lo referente a la sentencia, cabe señalar que todo proceso debe culminar con una resolución fundada en derecho, es decir, debidamente motivado. $\mathrm{Al}$ respecto, la Corte Interamericana precisó que

la motivación «es la exteriorización de la justificación razonada que permite llegar a una conclusión». El deber de motivar las resoluciones es una garantía vinculada con la correcta administración de justicia, que protege el derecho de los ciudadanos a ser juzgados por las razones que el Derecho suministra, y otorga credibilidad de las decisiones jurídicas en el marco de una sociedad democrática [...]. [L]as decisiones que adopten los órganos internos, que puedan afectar derechos humanos, deben estar debidamente fundamentadas, pues de lo contrario serían decisiones arbitrarias. En este sentido, la argumentación de un fallo debe mostrar que han sido debidamente tomados en cuenta los alegatos de las partes y que el conjunto de pruebas ha sido analizado. Asimismo, la motivación demuestra a las partes que éstas han sido oídas y, en aquellos casos en que las decisiones son recurribles, les proporciona la posibilidad de criticar la resolución y lograr un nuevo examen de la cuestión ante las instancias superiores. Por todo ello, el deber de motivación es una de las «debidas garantías» incluidas en el artículo 8.1 de la Convención para salvaguardar el derecho a un debido proceso. (Caso Tristán Donoso vs. Panamá. Sentencia del 27 de enero del 2009, párrafos 152 y 153).

\subsection{La inferencia probatoria como mecanismo para obtener una resolución judicial debidamente motivada}

Hasta estos momentos, hemos apreciado de manera genérica la importancia de la relación entre el derecho a la valoración de los medios probatorios con las motivaciones de las resoluciones judiciales para la tutela de los derechos fundamentales. 
Ahora, nos toca ingresar al análisis propiamente de la inferencia probatoria como mecanismo de obtención de una resolución judicial debidamente motivada. Esto implica — como hemos señalado - centrar nuestro estudio dentro de las reglas de la sana crítica como sistema de valoración de prueba y analizar cada uno de sus componentes para comprender cómo deben constituirse las decisiones de los juzgadores. Para ello, estamos convencidos, en primer lugar, de que debemos puntualizar de qué manera las reglas de la sana crítica influyen en las decisiones de los jueces, para, posteriormente, ingresar al estudio de la motivación de las resoluciones judiciales.

Así, la — libre - valoración de la prueba se concibe como una actividad racional para comprobar la verdad de las afirmaciones por las partes procesales, a la luz de las pruebas disponibles en el proceso. Lo que significa comprender la relación intrínseca entre prueba y verdad, y aceptar la concepción cognoscitivista antes que la persuasiva - pues no son equivalentes-, ya que la primera se encuentra preocupada por el plano objetivo (apreciación desde el juez) y la segunda, por el plano subjetivo (apreciación desde los abogados).

Por otro lado, es necesario comprender que el sistema de valoración de prueba (reglas de la sana crítica) comprende: las reglas de la lógica, las máximas de experiencia y las reglas de la ciencia. Precisamente aquellos contenidos muchas veces no son conocidos de forma adecuada por los jueces, lo que provoca constantes vulneraciones a los derechos, pues las decisiones arbitrarias que se emiten son frecuentes.

$\mathrm{Y}$ es que un correcto entendimiento del principio de libre valoración de prueba implica: 1) que el juez es libre en el sentido que no está sometido a reglas jurídicas que imponen un determinado valorar a las pruebas; y 2) que esa valoración no está sujeta a la moral subjetiva del juez, ni a sus sentimientos, intuiciones o emociones, sino a criterios de racionalidad cognoscitiva, susceptibles de ser compartidos y controlados intersubjetivamente, dicho de otra forma, no se trata de que el juez realice un «juicio de valor» o una valoración ética de las pruebas («debidas o indebidas», «justas o injustas»), sino una valoración epistémica, a la luz de los criterios de valoración probatoria que rigen en las ciencias empíricas ${ }^{1}$. Sólo si se entiende así, el principio

1 Para decidir si un hecho determinado ha sido probado por el juez, se debe valorar la prueba producida durante el proceso. Pero esta valoración es del mismo tipo de la valoración de la prueba en las ciencias empíricas. No se trata aquí de la valoración ética, sino de un tipo espe- 
de libre valoración es compatible con el deber de los jueces de motivar sus resoluciones, de otro modo, se abre un gran espacio para la arbitrariedad (Alchourrón, C. y Bulygin, E. citados por Zavaleta, 2014, p. 356).

Siendo así, las reglas de la lógica están diseñadas en función de la lógica dialéctica y no la del simple silogismo, es decir, la lógica formal proposicional no será suficiente para enfrentar el reto de la valoración de prueba. Lo mismo ocurre con las reglas de las máximas de experiencia, que son generalizaciones con validez universal que expresan habitualidad en ciertas situaciones o conductas que pueden ser utilizadas al momento de decidir. Mientras que las reglas de la ciencia se someten a los nuevos avances tecnológicos recaídos en estudios de otras disciplinas especializadas que complementan la certeza y/o convicción del juez para emitir una decisión justa.

En cuanto a la motivación de resoluciones judiciales, podemos señalar que el estudio es umbilical con la valoración de prueba. Y según Taruffo (2013), el fenómeno de la prueba de los hechos y el de la motivación de la sentencia tienen entre sí una conexión muy estrecha, casi de recíproca implicación, en el ámbito de una concepción racionalista de la decisión judicial.

Por eso, la motivación, en cuanto pública manifestación de las razones que pretenden justificar la decisión, es una garantía frente la arbitrariedad. Bentham ya lo había advertido tempranamente: la publicidad «es el preservativo de la arbitrariedad» (1971, p. 85); «lo que menos se debe temer de los jueces son los poderes discrecionales que sólo se les confía con la condición expresa de que motiven en todos los casos el uso que hacen de ellos. Ese freno es suficiente, porque les deja toda la responsabilidad.» (Bentham 1971, p. 85).

Ahora bien, la motivación de las resoluciones judiciales es el fiel reflejo del principio del Estado Constitucional, estas deben ser fundamentadas porque las decisiones jurídicas no son evidentes y podrían ser arbitrarias.

cial de valoración, a falta de un término mejor, la llamaremos valoración epistémica. Al valor de la prueba no formulamos juicios de valor genuinos y en todo caso la clase de valores que aparecen en este contexto nada tienen que ver con los «valores humanos» incorporados a las normas jurídicas; pruebas fácticas no son valoradas como correctas o incorrectas, debidas o indebidas justas o injustas, convenientes o inconvenientes, sino como conducentes o no (y en qué grado) a la verdad de oraciones empíricas (Alchourrón, C. y Bulygin, E. citados por Zavaleta, 2014, p. 356). 
Además, conforme nos enseña el compendio de lectura del programa, los argumentos esgrimidos en la sentencia deben ser congruentes, coherentes, razonables y estar fundados en derecho, vale decir, de acuerdo con el ordenamiento jurídico.

\subsection{Caso planteado: análisis de la motivación en una resolución específica}

El caso planteado está vinculado con la sentencia del Tribunal Constitucional recaída en el expediente $\mathrm{N} .^{\circ} 728-2008-\mathrm{HC} / \mathrm{TC}$, que declaró la nulidad de la sentencia emitida por el Poder Judicial (Primera Sala Transitoria Penal de la Corte Suprema), por vulnerar frontalmente el respeto a la motivación de las decisiones judiciales, específicamente la valoración de los medios probatorios, al condenar a Guiliana Llamoja por el delito de homicidio calificado de su madre. La sentencia del Tribunal Constitucional advierte que no se ha cumplido con explicitar qué reglas de la lógica, qué máximas de la experiencia o qué conocimientos científicos justificaron el paso de los hechos probatorios a los hechos probados.

\section{CONCLUSIÓN}

Sólo podrá obtenerse una resolución judicial debidamente motivada siempre que las decisiones contengan una valoración de los medios probatorios, de acuerdo con las reglas de la sana crítica. Con ello podemos consagrar una verdadera protección a los derechos fundamentales.

La tarea que nos toca asumir es profundizar los conocimientos sobre esas reglas de valoración, bajo un enfoque objetivo y coherente que nos permita conocer el mundo de las inferencias probatorias.

\section{BIBLIOGRAFÍA}

Álvaro, C. (2008). El derecho a la tutela jurisdiccional desde la perspectiva de los derechos fundamentales. Jornadas Iberoamericanas de Derecho Procesal. Lima: Universidad de Lima.

Bentham, J. (1971) Tratado de las pruebas judiciales. Trad. de M. Ossorio. Buenos Aires: EJEA.

Eguiguren, F. (1999). La inejecución de sentencias por incumplimiento de entidades estatales. Algunas propuestas de solución. Ius et veritas. 18, Lima: PUCP; pp.96-107. 
Monroy, J. Teoría general del proceso. Lima: Communitas; 2008.

Priori, G. (2003). La efectiva tutela jurisdiccional de las situaciones jurídicas materiales. Ius et veritas. 26. Lima: PUCP.

Taruffo, M. (2013). Verdad, prueba y motivación en la decisión sobre los hechos. Serie Cuadernos de Divulgación de la Justicia Electoral 20. México: Tribunal Electoral del Poder Judicial de la Federación.

Ticona, V. El debido proceso y la demanda civil. Tomo I. Lima: Rodhas; 1999.

Zavaleta, R. La motivación de las resoluciones judiciales como argumentación jurídica. Lima: Grijley; 2014. 